\title{
O CICLO DA VESÍCULA SINÁPTICA: PANORAMA MOLECULAR*
}

\author{
THE SYNAPTIC VESICLE CYCLE: A MOLECULAR OVERVIEW
}

Gabriel M. Arisi ${ }^{1}$, Luciano Neder² \& Jorge E. Moreira ${ }^{3}$

\begin{abstract}
Alunos de pós-graduação da Faculdade de Medicina de Ribeirão Preto (FMRP) da Universidade de São Paulo (USP), nos Departamentos de ${ }^{1}$ Biologia Celular e Molecular e Bioagentes Patogênicos e ${ }^{2}$ Patologia. ${ }^{3}$ Professor do Curso de Pós Graduação RMF 5751, "Aspectos Moleculares da Transmissão Sináptica" do Departamento de Biologia Celular e Molecular e Bioagentes Patogênicos, FMRP-USP.

CorrespondÊncia: Prof.Dr. Jorge E. Moreira, Departamento de Biologia Celular e Molecular e Bioagentes Patogênicos, FMRP-USP. Av.Bandeirantes, 3900. 14049-900, Ribeirão Preto, SP. e-mail: cello@fmrp.usp.br
\end{abstract}

ARISI GM; NEDER L \& MOREIRA JE. O ciclo da vesícula sináptica: panorama molecular. Medicina, Ribeirão Preto, 34: 154-169, abr./jun. 2001.

RESUMO: A presente revisão aborda um ponto específico dentro da sinapse, provavelmente o mais crucial: as interações moleculares entre proteínas da membrana das vesículas sinápticas e da membrana plasmática pré-sináptica. Uma linguagem molecular muito precisa permite a fusão entre as membranas da vesícula sináptica e a plasmática, fusão que libera o neurotransmissor contido na vesícula para a fenda sináptica. A vesícula sináptica foi alvo, nos últimos anos, de uma verdadeira dissecção molecular. É a organela celular com a mais completa descrição estrutural e cinética de seus componentes protéicos. A descoberta de famílias de proteínas homólogas, presentes em todos os tipos celulares eucariotos, como a Rab e a SNARE (SNAP receptors), demonstrou que o ciclo da vesícula sináptica é uma interação entre sistemas protéicos, universais e específicos, de regulação do tráfego vesicular e de fusão de membranas lipídicas. O endereçamento e o controle do fluxo das estruturas precursoras das vesículas sinápticas até o terminal sináptico são realizados pela família Rab de pequenas GTPases. As proteínas da superfamília das kinesinas são as responsáveis pela ação mecânica no transporte anterógrado das estruturas precursoras, ao longo dos microtúbulos do citoesqueleto axonal. As proteínas SNARE realizam a fusão das vesículas com a membrana do terminal pré-sináptico. A proteína sinaptotagmina controla a formação do complexo SNARE em um modo dependente de cálcio. Embora já se tenha conhecimento da maior parte das proteínas envolvidas no ciclo da vesícula sináptica, tem-se ainda que elucidar muitas das funções e interrelações entre elas.

UNITERMOS: Vesículas Sinápticas. Proteínas Sinápticas. Sinapse. Neurotransmissores.

\section{INTRODUÇÃO}

Considerando o aperfeiçoamento intelectual do homem ao longo de milhares de anos, é surpreendente que o estudo do sistema nervoso, que seria o maior legado da espécie, seja a mais nova das biociências.
Até o século XVII, os nervos eram considerados estreitos tubos que terminavam em músculos ou glândulas, conduzindo os humores ou fluxos dos espíritos animais $^{(1)}$. Neurônios foram individualizados somente 160 anos atrás ${ }^{(2)}$ embora as células de Purkinje do cerebelo sejam tão grandes que poderiam ser obser-

\footnotetext{
* Resultados de discussões e seminários relizados durante o curso RMF 5751, "Aspectos Moleculares da Transmissão Sináptica", entre 31 de agosto e 30 de setembro de 2000. Uma atualização da literatura foi realizada antes da submissão do manuscrito.
} 
vadas e dissecadas com uma lupa de mão ${ }^{(3)}$. A teoria neuronal, que forma atualmente o verdadeiro cerne da neurociência, foi proposta há pouco mais de 100 anos por Ramón y Cajal ${ }^{(4)}$. Mais chocante ainda é considerar que a primeira hipótese sobre a sinapse química foi apresentada há menos de $50 \operatorname{anos}^{(5)}$ e confirmada há apenas trinta anos ${ }^{(6)}$.

Entretanto, a década passada foi, historicamente, a de maior interesse na biologia dos processos mentais. Por isso foi chamada "a década do cérebro" pela maior agência financiadora de pesquisa do mundo o NIH (National Institutes of Health) dos Estados Unidos. Tudo faz supor que esse interesse tenda a aumentar e que o estudo do cérebro seja, para o século XXI, o que o estudo dos genes foi para o século passado.

O trabalho dos neurobiólogos, nas últimas décadas, explicou inúmeras questões sobre a estrutura molecular e as funções do sistema nervoso que, por sua vez, responderam problemas conhecidos de longa data, nas áreas clínicas, neurológica, psiquiátrica e neuropsiquiátrica. Entretanto, o aspecto mais provocante desses avanços científicos aponta para a compreensão das mais altas funções cognitivas, entendendo-se as bases físicas da consciência, dos processos mentais pelos quais percebemos, atuamos, aprendemos e lembramos. É relevante destacar que o prêmio Nobel de Medicina e Fisiologia, 2000, acaba de ser concedido a Paul Greengard, Eric Kandel e Arvid Carlsson, pelo resultado de seus trabalhos nesta área do conhecimento. Muitos destes trabalhos são motivo de nossa revisão anterior ${ }^{(7)}$ e da presente revisão.

Em nossa revisão anterior ${ }^{(7)}$, discutimos amplamente aspectos moleculares das relações interneuronais e da sinapse, o contato especializado entre neurônios, como elemento autônomo e unidade de funcionamento do sistema nervoso.

A presente revisão, aborda um ponto específico dentro da sinapse, provavelmente o mais crucial: as interações moleculares entre proteínas da membrana das vesículas sinápticas (VS) e da membrana plasmática pré-sináptica. Uma linguagem molecular muito precisa permite a fusão entre as membranas da vesícula sináptica (MV) e plasmática (MP). Essa fusão libera o neurotransmissor (NT) contido na vesícula, na fenda sináptica. Tais fenômenos constituem os primórdios das atividades motoras e sensitivas do sistema nervoso e do fenômeno consciente. A fusão somente ocorre em regiões especializadas de contato da membrana que constituem as sinapses, ocorrendo a posterior reciclagem das vesículas por endocitose de regiões da membrana plasmática.

Apesar das características exclusivas da exocitose dos neurotransmissores, como sua velocidade, dependência de cálcio e plasticidade, a descoberta de famílias de proteínas homólogas em todos os tipos celulares eucariotos, como a Rab,composta por GTPases que direcionam o tráfego vesicular ${ }^{(8,9,10)}$, e a família SNARE, que forma um complexo de ancoramento e fusão ${ }^{(11 / 14)}$, demonstrou que o ciclo da vesícula sináptica é uma interação entre sistemas protéicos, universais e específicos, de regulação do tráfego vesicular e de fusão de membranas lipídicas ${ }^{(15)}$.

Vesículas sinápticas podem ser classificadas, de acordo com sua morfologia, em três tipos ${ }^{(16)}$ : vesículas sinápticas pequenas (VSP), que contêm aminoácidos, vesículas grandes de centro denso (VGCD), que contêm neuropeptídeos, e vesículas pequenas de centro denso (VPCD), que contêm catecolaminas. Glutamato, ácido $\gamma$-aminobutírico (GABA), acetilcolina e glicina são exemplos de aminoácidos neurotransmissores, os chamados neurotransmissores "clássicos". Vasopressina, substância $P$, galanina e ß-endorfina são exemplos de neuropeptídeos ${ }^{(17)}$; dopamina, norepinefrina e epinefrina são exemplos de catecolaminas ${ }^{(18)}$.

Quando visualizadas ao microscópio eletrônico (Figura 1), as VSP apresentam-se esféricas, translúcidas e possuem diâmetro de $\sim 50 \mathrm{~nm}$. As vesículas de centro denso (VCD), assim chamadas por sua alta densidade eletrônica ao microscópio eletrônico, têm diâmetros maiores (80-200 nm). Entre estas, as vesículas que contêm neuropeptídeos (VGCD) são maiores que as que contêm catecolaminas (VPCD).

\section{CICLO DA VESÍCULA SINÁPTICA}

O ciclo da vesícula sináptica pode ser dividido, de acordo com aspectos funcionais, em biogênese, transporte, translocação do neurotransmissor, exocitose e endocitose (Figura 2).

\subsection{Biogênese}

A biogênese tem início com a síntese das proteínas membranares (da MV e da MP) no Retículo Endoplasmático Rugoso (RER), no corpo celular do neurônio. A translocação das proteínas através da membrana reticular é direcionada, por peptídeos sinalizadores, que se ligam às proteínas receptoras de sinal (PRSs) e por maquinário translocacional. Entretanto, algumas proteínas da MV, como sinaptobrevina, 

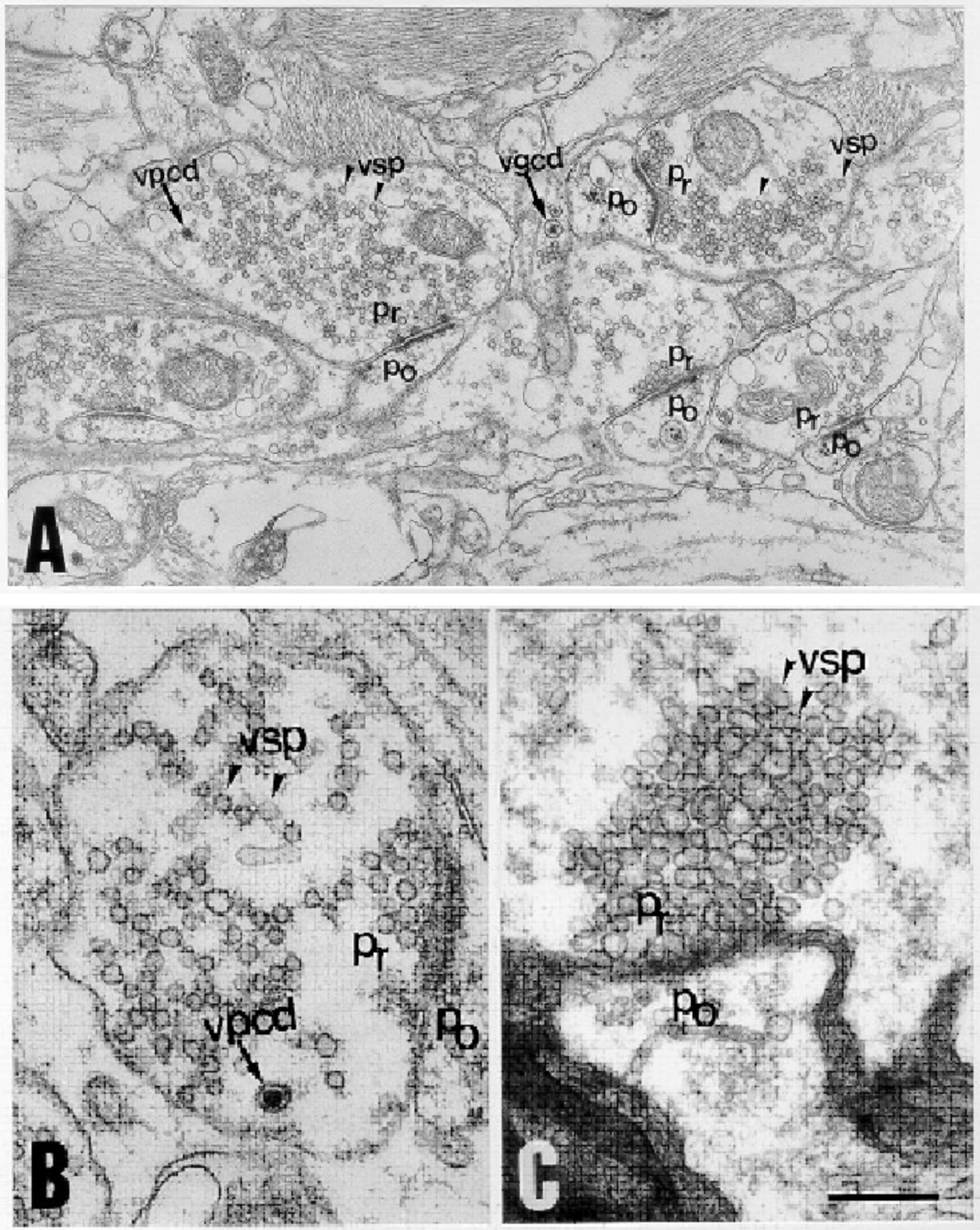

Figura 1- Sinapses sobre dendritos apicais de células piramidais de CA1 do hipocampo humano (A e B). Os terminais pré-sinápticos (pr) contatam botões dendríticos pós-sinápticos (po). A maior parte das vesículas sinápticas são pequenas (vsp), do tipo transportador de neurotransmissores clássicos (aminoácidos). Poucas vesículas pequenas de centro denso, transportadoras de neuropeptídeos (vpcd) e uma grande de centro denso ( $\mathrm{vgcd}$ ) transportadora de catecolaminas são assinaladas. Em $\mathrm{C}$, uma sinapse motora, provavelmente inibitória por suas vesículas pequenas, pleomórficas, na sinapse gigante da lula Loligo pealii. Barra em A=625 nm em B e C=250 nm. Eletromicrografias inéditas dos autores. 


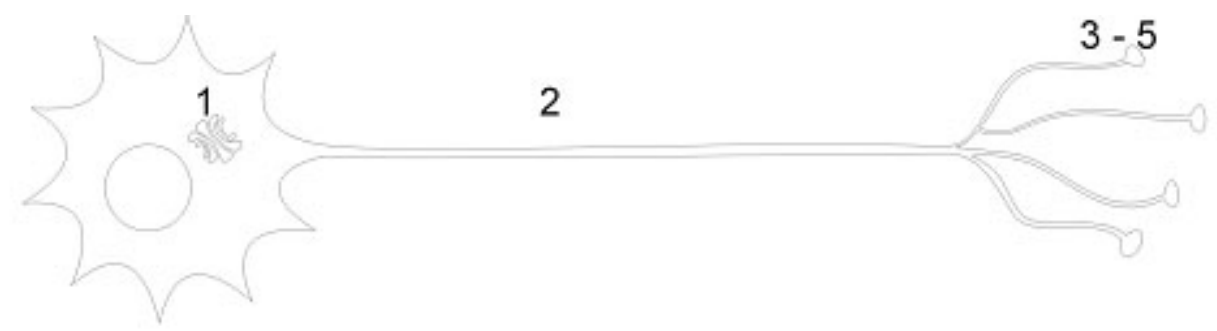

1. Biogênese
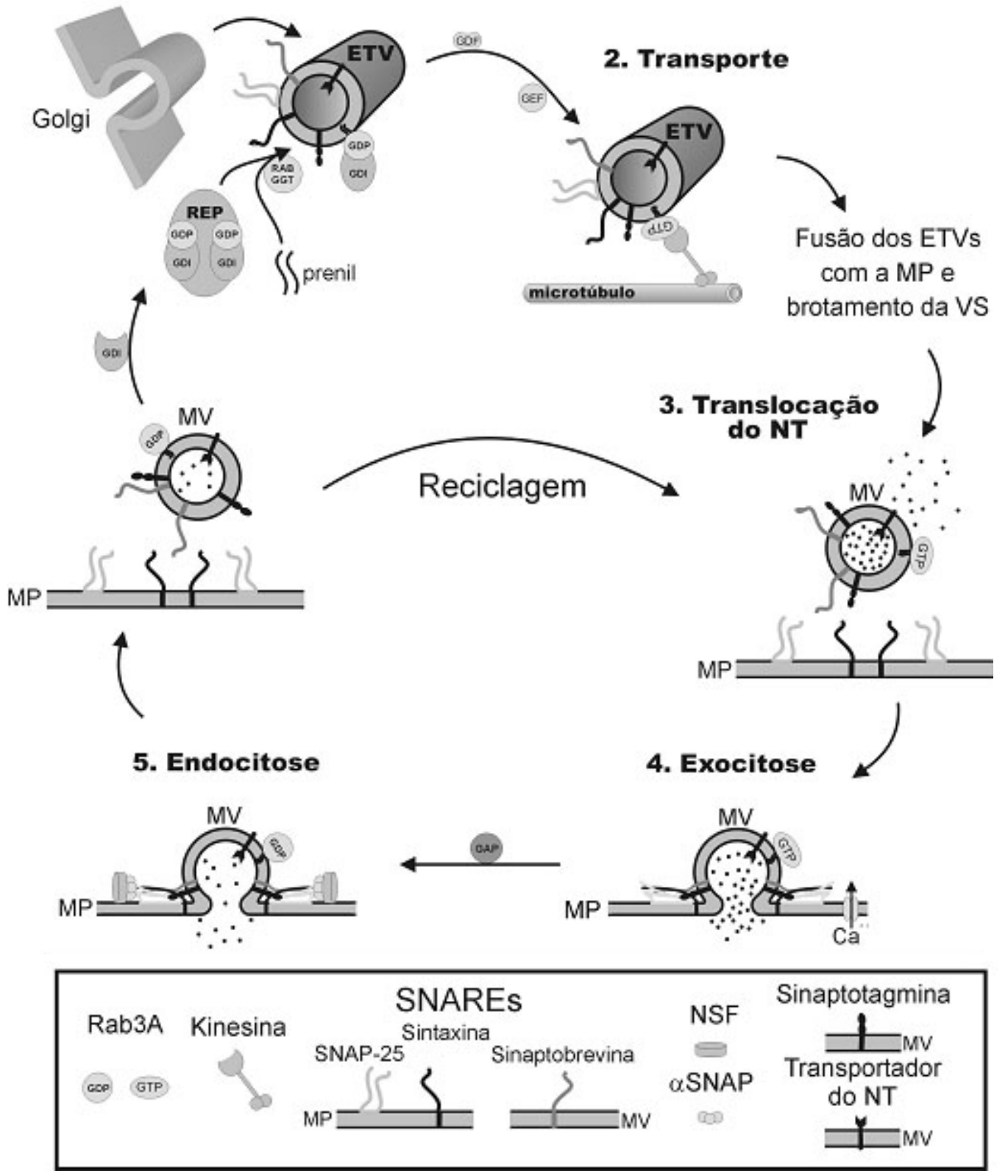

Figura 2 - Ciclo da vesícula sináptica: 1. Biogênese a partir do complexo de Golgi. 2. Transporte das ETVs (estruturas túbulovesiculares) ao longo dos microtúbulos axonais. É importante salientar que foi representada uma ETV com todas as proteínas sinápticas, embora isso não ocorra in vivo. 3. Translocação do neurotransmissor do citoplasma para o lúmen da vesícula. 4. Exocitose do neurotransmissor através do poro formado pela fusão das membranas vesicular e plasmática (veja estrutura do complexo central SNARE, na fig. 4). 5. Endocitose para a reciclagem de proteínas e fosfolipídios (para maior clareza não foram representadas as estruturas de clatrina e dinamina, ver fig. 5). No topo da figura, esquema de uma célula neuronal, mostrando as regiões onde ocorre cada um dos passos do ciclo. 
e proteínas da MP, como sintaxina, são inseridas após sua tradução, independentemente de PRSs e proteínas translocacionais, pois seus domínios transmembranares são C-terminais. Portanto, a síntese da proteína está completa antes de seu reconhecimento pela maquinaria translocacional ${ }^{(16)}$.

Membranas contendo as proteínas da MV e MP são, então, direcionadas para o Complexo de Golgi, onde, após vários ciclos de fusão e brotamento, emer- gem como estruturas túbulo-vesiculares (ETVs) em forma de cilindros que possuem entre 50 e $80 \mathrm{~nm}$ de comprimento $^{(19)}$. As ETVs são precursoras das VSP e serão transportadas por proteínas transportadoras (kinesinas) sobre microtúbulos ao longo do axônio até o terminal (20) (Figura 3). Após a chegada das ETVs ao terminal pré-sináptico (ver Transporte, adiante) estas fundem-se à MP em um modo não controlado por cálcio.
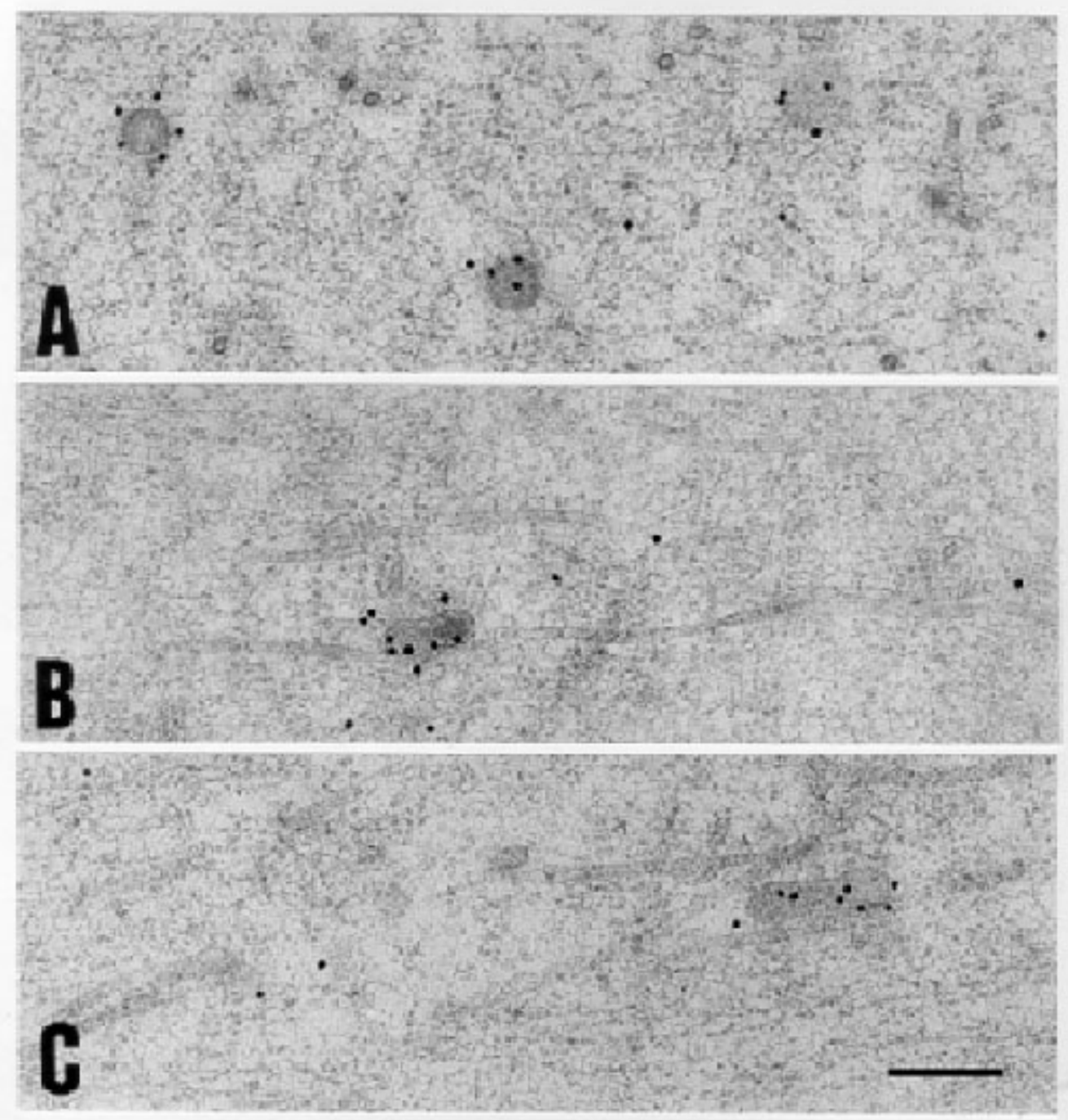

Figura 3- Cortes finos de axoplasma extruído do axônio gigante da lula Loligo pealii, preservado mediante congelamento rápido e substituição a baixas temperaturas e incubado com anticorpo contra a proteína motora kinesina mediante o método da proteína $\mathrm{A}$ conjugada a ouro coloidal (partículas de $15 \mathrm{~nm}$ ). A kinesina é um transportador anterógrado (corpo neuronal $P$ terminal axonal), ao longo de microtúbulos que lhe servem de trilhos. Em A, vesículas em transporte axonal, mostram partículas de ouro que apontam moléculas de kinesina. A quantidade de kinesina ligada às vesiculas é alta pois em uma seção de $80 \mathrm{~nm}$, podemos ver até cinco moléculas em volta de uma vesícula, como se observa na vesícula acima, à esquerda. B e C mostram estruturas túbulovesiculares (ETV) transportadoras de proteínas de membrana, também carregadas por kinesina. A relação entre a kinesina, as cisternas em transporte e os microtúbulos é quase óbvia em B onde as partículas de ouro parecem rodas na estrutura que é transportada ao longo do microtúbulo. Barra: $200 \mathrm{~nm}$. Eletromicrografias inéditas de Jorge E. Moreira. 


\subsection{Transporte anterógrado}

\subsubsection{Rabs}

$\mathrm{O}$ endereçamento e o controle do fluxo das estruturas precursoras das VS até o terminal sináptico é realizado pela família de pequenas guanosina trifosfatases (GTPases) denominadas proteínas Rab. Já foram identificados, aproximadamente quarenta tipos de Rabs, incluindo as isoformas Rab3A e Rab3C presentes nas $\mathrm{VS}^{(10)}$. As proteínas Rabs ciclam entre os estados ativo (ligado à GTP) e inativo (ligado à GDP) através da ação de várias proteínas efetoras. Utilizaremos o ciclo da Rab3A como modelo (Figura 2), pois esta proteína é expressa em todas as células neuronais ${ }^{(10)}$.

As proteínas Rabs são mantidas inativas no citosol, ligadas à GDP pelo Rab GDI (GDPdissociating inhibitor, Inibidor da Dissociação do GDP) e ligadas também à REP (Rab Escort Protein, Proteína Acompanhante de Rab), que se liga às Rabs não preniladas, prevenindo assim, sua ligação não específica.

O transporte tem seu início com o ancoramento da proteína Rab3A-GDP na face citoplasmática das ETVs. Ele se dá através da adição covalente de dois grupos geranilgeranil via ligações tioéster a cisteínas C-terminais, ou seja, através da isoprenilação da Rab3A, o que a libera da REP. Os grupos hidrofóbicos funcionam como âncoras, ligando $\mathrm{a}$ Rab à membrana da ETV. A enzimologia da prenilação das Rabs, uma reação catalizada pela Rab geranilgeranil transferase (RabGGT), foi caracterizada ${ }^{(21)}$, bem como a estrutura da RabGGT ${ }^{(22)}$.

Após o ancoramento da Rab3A-GDP, o GDI é retirado por GDF (GDI Displacement Factor, Fator de Deslocamento de GDI). A troca de GDP por GTP é catalizada por GEF (Guanine Exchange Factor, Fator de Troca de Guanina) ativando a Rab3A e tornando-a resistente a sua remoção da MV pelo Rab GDI. O GTP é hidrolisado pela atividade de GTPase, intrínseca da proteína Rab3A. A barreira para a transição de estado é baixada por GAPs (GTPase-activating proteins, Proteínas Ativadoras de GTPases). Uma vez que a fusão vesícula-MP tenha ocorrido, o GDI libera a forma Rab3A-GDP para o citoplasma e o ciclo pode reiniciar ${ }^{(9)}$.

As proteínas Rab atuam no recrutamento das proteínas SNARE para a membrana a ser destacada e isto foi comprovado na interação existente entre as SNARE e a proteína Rab1, no retículo endoplasmático, através da proteína p115 ${ }^{(23)}$. A Rab3A interage também com a proteína Rabfilina- $3 \mathrm{~A}^{(24)}$. Com a hidrólise do GTP, a Rabfilina-3A estimula a $\alpha$-actinina, uma proteína que forma feixes de actina através da ligação cruzada de filamentos ${ }^{(25)}$. A atividade da Rabfilina-3A é inibida pela Rab3A-GTP. Assim sendo, a Rabfilina$3 \mathrm{~A}$ pode ser uma importante conexão entre a Rab3A e proteínas do citoesqueleto, realizando o papel de "fator de enlaçamento"(26). Esses fatores foram descritos em Saccharomyces cerevisiae que possui proteínas como, por exemplo, o Exocisto ${ }^{(27)}$. Portanto, as Rabs agiriam também no recrutamento de fatores de enlaçamento, coordenando-os com eventos posteriores como a formação do complexo SNARE ${ }^{(28)}$.

\subsubsection{Kinesinas}

As proteínas da superfamília das kinesinas (KIF) são as responsáveis pela ação mecânica no transporte anterógrado (corpo celular $\rightarrow$ sinapse) das ETVs percursoras ao longo dos microtúbulos do citoesqueleto axonal $^{(29)}$ (Figura 3). As mecanoenzimas KIF1A, KIF3A e KIF3B são neuroespecíficas e transportam diferentes tipos de ETVs. A KIF1A, por exemplo, transporta ETVs com as proteínas sinaptofisina e sinaptotagmina em conjunto com a Rab3A, mas essas ETVs não contêm sintaxina1A, SV2 ou SNAP-25. Portanto, as proteínas de membrana são distribuídas em diferentes classes de ETVs de transporte no corpo celular e são transportadas por sua kinesina motora específica ao longo do axônio ${ }^{(30)}$. Até dez moléculas de KIF1A podem estar presentes em uma ETV e a velocidade de deslocamento ao longo de um microtúbulo, é de $1,5 \mu \mathrm{m} / \mathrm{s}$, sendo esta a mais rápida das KIFs. Embora essa velocidade pareça mínima, seria equivalente à de um carro ao viajar em uma auto-estrada a aproximadamente $500 \mathrm{~km} / \mathrm{h}$, de acordo com a relação tamanho/deslocamento! As proteínas KIF3A e KIF3B formam um heterodímero que, por sua vez, associase à KAP3 (Proteína Associada à KIF3), responsável pela ligação do heterodímero KIF3A/3B à estrutura tubulovesicular transportadora ${ }^{(31)}$.

Ainda não foi estabelecido como se dá a interação entre a Rab3A e a KIF1A. No entanto, foi identificada uma nova proteína da superfamília das kinesinas que interage com a Rab6-GTP, denominada Rabkinesina-6. Esta é responsável pelo transporte Golgi $\rightarrow$ Retículo Endoplasmático ${ }^{(32)}$. Estabelece-se, assim, uma conexão entre o controle exercido pelas Rabs e a ação motora realizada pelas kinesinas no transporte vesicular. 


\subsection{Translocação do neurotransmissor}

Os neurotransmissores clássicos são sintetizados no citoplasma do terminal pré-sináptico, sendo necessárias, portanto, proteínas que os transportem para dentro da vesícula, atravessando a membrana vesicular ${ }^{(33)}$. Foram identificados distintos transportadores vesiculares para monoaminas (VMAT), acetilcolina (VAChT), GABA (VGAT) e glutamato (VGLUT). Todos dependem de um gradiente eletroquímico protônico $\Delta \mu_{\mathrm{H}+}$, gerado pela bomba de prótons $\mathrm{H}^{+}$-ATPase vesicular, para cruzar a MV. O gradiente eletroquímico $\Delta \mu_{\mathrm{H}+}$ é a soma de um componente químico $\Delta \mathrm{pH}$ e um componente elétrico $\Delta \psi$. O transporte de monoaminas e acetilcolina ( $\mathrm{ACh}$ ) envolve a troca de prótons do lúmen da vesícula por neurotransmissores do citoplasma, dependendo primariamente do componente químico $(\Delta \mathrm{pH})$ do gradiente protônico. A clonagem desses transportadores (monoaminas e ACh) demonstrou sua estreita relação estrutural, ambos possuindo doze domínios transmenbranares (DTMs). Em contraste, o transportador vesicular para glutamato depende quase inteiramente do componente elétrico $(\Delta \psi)$ do $\Delta \mu_{\mathrm{H}+}$, e o transportador de GABA parece depender igualmente em ambos, $\Delta \mathrm{pH}$ e $\Delta \psi$, possuindo $\operatorname{dez}$ DTMs $^{(34)}$.

Foi proposto que a glicoproteína SV2, presente na MV, fosse um transportador de neurotransmissores $^{(35)}$ devido à sua estrutura, com doze DTMs, homóloga a transportadores. No entanto, nenhuma atividade transportadora foi detectada. Mais recentemente, foi sugerido um papel no processo de fusão para SV2, em uma interação regulada por $\mathrm{Ca}^{2+}$ com $\operatorname{sinaptotagmina}^{(36)}$. A descrição de uma proteína distantemente relacionada a SV2, chamada $\mathrm{SVOP}^{(37)}$, também com doze DTMs e de função desconhecida, sugere um papel estrutural para SV2 na manutenção da grande curvatura da membrana vesicular. Ainda é um mistério o papel da proteína SV2 na vesícula sináptica.

Os transportadores atuam também na plasticidade sináptica, modulando o quantum do neurotransmissor. Trabalhos com camundongos knock-out para o gene VMAT2 demonstraram que o nível de expressão do transportador regula o carregamento de neurotransmissor e a quantidade de VSP disponíveis para exocitose $^{(38)}$.

\subsection{Exocitose}

É a etapa mais importante do ciclo e, portanto, a mais estudada no contexto molecular. A exocitose envolve a aproximação e fusão das vesículas sinápticas com a membrana pré-sináptica. A hipótese da existência de receptores nas membranas, vesicular e plasmática, foi proposta por Palade em seu clássico artigo sobre "síntese protéica" (39). Estudos recentes ${ }^{(40-45)}$ confirmaram a hipótese de receptores nas membranas, porém a descrição completa do mecanismo de interação ainda está incompleta.

\subsubsection{SNARE}

As proteínas SNARE (SNAP receptors, Receptores para SNAP) foram descobertas independentemente em neurônios ${ }^{(40)}$ e fungos ${ }^{(41)}$, mas, posteriormente, foram descritas também em plantas ${ }^{(42)}$. Sinaptobrevina $^{(43)}$, sintaxina ${ }^{(44)}$ e SNAP- ${ }^{(45)}$ (synaptossomeassociated protein of $25 \mathrm{kDa}$, Proteína Associada à Sinaptossoma de $25 \mathrm{kDa}$ ) são "membros fundadores" da superfamília SNARE, caracterizada por um motivo de 60 aminoácidos (aa) em $\alpha$-hélice ${ }^{(46)}$.

As proteínas SNARE da MP (sintaxina e SNAP-25) e MV (sinaptobrevina) realizam a aproximação e a fusão entre as membranas do terminal sináptico através da formação do complexo central entre sinaptobrevina 2, sintaxina-1A e SNAP-25, com uma estequiometria de 1:1:1 (Figuras 4A e 4B). A formação desse complexo ternário estável ocorre através da interação dos resíduos hidrofóbicos das $\alpha$-hélices dos motivos $\operatorname{SNARE}^{(47)}$ e da interação eletrostática entre resíduos centrais de arginina e glutamina, formando um feixe em coiled-coil (Figura 4C). A interação eletrostática está protegida da água citoplasmática pelas camadas de aminoácidos hidrofóbicos, conferindo grande estabilidade ao complexo.

As proteínas SNARE são classificadas pela presença de um resíduo central de arginina (Q-SNARE) ou de glutamina (R-SNARE) no motivo SNARE $^{(48)}$. Sintaxina e SNAP-25 são Q-SNAREs; sinaptobrevina é R-SNARE. O complexo central é composto por quatro motivos SNARE, um da sinaptobrevina, um da sintaxina e dois da SNAP-25(11), três Q-SNARE e um R-SNARE, portanto; o que parece ser um princípio universal dos complexos SNARE ${ }^{(49)}$. A proteína SNAP-25 possui dois motivos Q-SNARE interligados por uma alça rica em cisteínas palmitoiladas, responsáveis por seu ancoramento à $\mathrm{MP}^{(50)}$. Sinaptobrevina e sintaxina estão embebidas nas membranas através de DTMs C-terminais. 
$\mathbf{A}$

$\mathbf{B}$
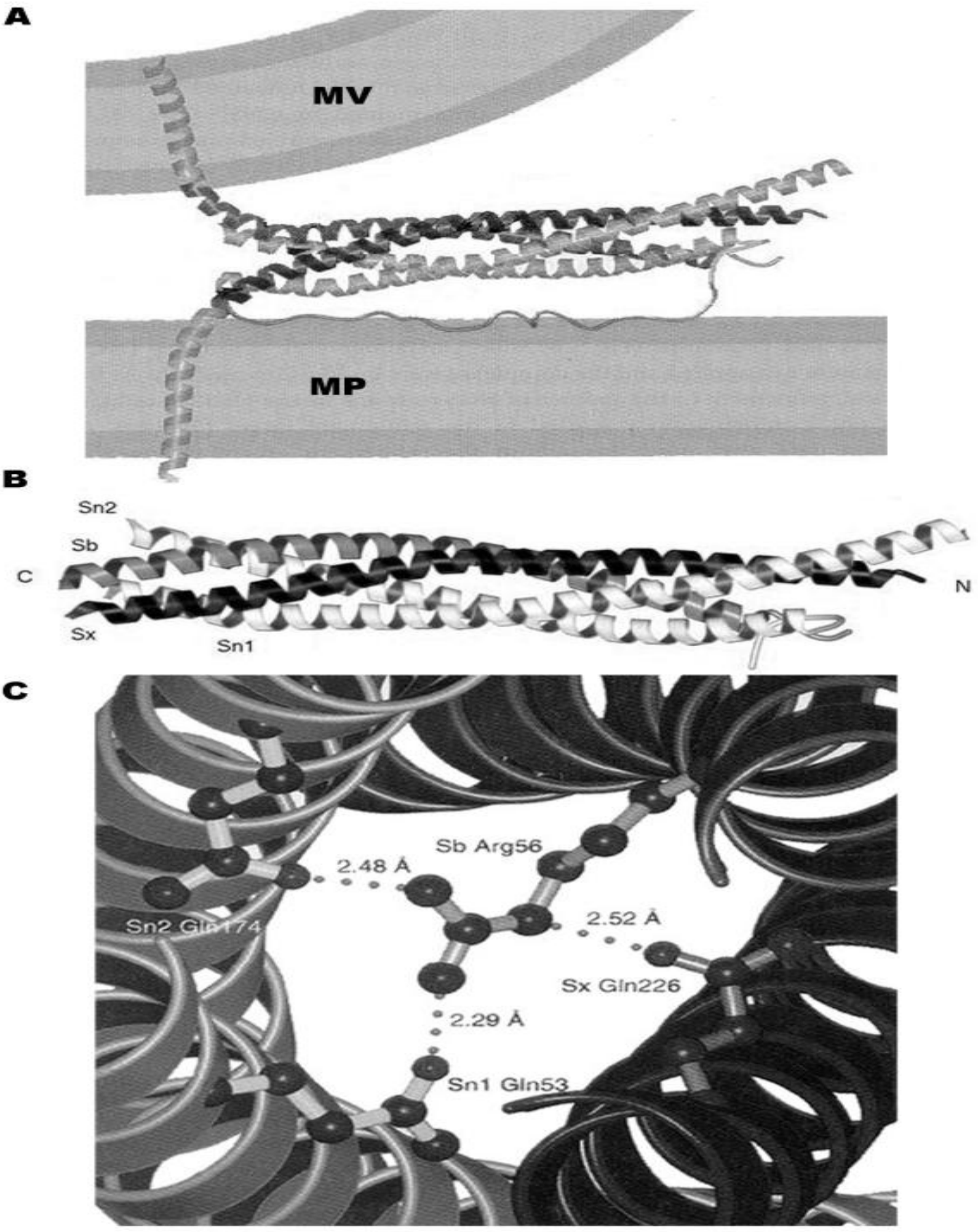

Figura 4 - Complexo central SNARE, posição entre a membrana vesicular (MV) e a membrana plasmática (MP) e domínios transmembranares (A). Identificação dos motivos SNARE (B): Sb, sinaptobrevina, Sx, sintaxina, Sn1, SNAP-25 (motivo 1) e Sn2, SNAP-25 (motivo 2), C, extremidade carboxil, N, extremidade amino. Vista frontal do complexo, mostrando a interação entre as cadeias laterais dos resíduos centrais de arginina (Arg) e glutamina (Gln) dos motivos SNARE. Modificado de Sutton et al. (11). 
Há controvérsias sobre a seletividade ${ }^{(40)}$ ou não-seletividade ${ }^{(13)}$ da interação entre as proteínas SNAREs. Se a interação for seletiva, explicará como ocorre o reconhecimento e especificidade tanto em fusões membranares homotípicas (compartimentos iguais) ou heterotípicas (compartimentos diferentes), caso seja o contrário, os SNAREs não são responsáveis pelo reconhecimento entre as membranas.

A hipótese que explica a nanomecânica de como a formação do complexo central aproxima e funde as membranas provém de estudos com as proteínas de fusão virais, especialmente da hemaglutinina influenzae (HA) ${ }^{(51)}$. A formação do complexo central aproximaria as membranas plasmática e vesicular e a formação de um agregado de complexos SNARE limitaria a difusão horizontal de fosfolipídios em ambas as membranas. Uma $\alpha$-hélice anfipática da sinaptobrevina (resíduos 38-55) agiria analogamente aos peptídeos de fusão virais, inserindo-se na camada externa da MV, desestabilizando-a ${ }^{(51,52)}$. A desestabilização geraria uma falha hidrofóbica que seria corrigida pelo fluxo de fosfolipídios da camada interna da MP, formando um pedúnculo (stalk), unindo as membranas. O pedúnculo evoluiria para um poro, de geometria toroidal, através do qual se daria a exocitose do neurotransmissor contido na VSP ${ }^{(53)}$. Essa fusão de bicamadas fosfolipídicas em meio aquoso envolve estados de transição em que os fosfolipídios não estão organizados em bicamadas e nos quais as monocamadas estão altamente curvadas ${ }^{(54)}$.

A dissolução do complexo SNARE é realizada pela chaperona NSF ( $N$-ethyl maleimide sensitive factor, fator sensível à $\mathrm{N}$-etil maleimide) em conjunto com a proteína adaptadora $\alpha$ - ou $\beta$-SNAP (soluble NSF attatchment protein, proteína solúvel anexa à $\mathrm{NSF}$, não relacionada à SNAP-25) ${ }^{(54)}$. A proteína NSF pertence à superfamília AAA (ATPases associadas a várias atividades celulares), caracterizada por um sítio de ligação com ATP, altamente conservado ${ }^{(55)}$. Após ligar-se ao complexo central, a proteína SNAP sofre uma mudança conformacional. A mudança permite a ligação da molécula hexamérica do NSF ao segmento $\mathrm{N}$-terminal do complexo central SNARE. Através da hidrólise de ATP, o NSF catalisa a dissolução do complexo central $\operatorname{SNARE}^{(56,57)}$.

\subsubsection{Canais de Cálcio}

A liberação do NT é controlada pelo influxo de íons de cálcio $\left(\mathrm{Ca}^{2+}\right)$, através de canais dependentes de voltagem, embebidos na MP pré-sináptica, despolarizada pela chegada do potencial de ação ${ }^{(58,59)}$. Os canais de $\mathrm{Ca}^{2+}$ do tipo P/Q e N estão presentes no terminal pré-sináptico ${ }^{(60)}$. A exocitose requer alta concentração de cálcio, a qual sobe de seu nível basal de $100 \mathrm{nM}$ para até $>200 \mu \mathrm{M}^{(61)}$, possuindo um limiar de $20-50 \mu \mathrm{M}^{(62)}$. Esse aumento na concentação de cálcio ocorre apenas nas proximidades dos canais, gerando microdomínios de $\mathrm{Ca}^{2+(61)}$. Os microdomínios seriam aumentos transientes da concentração de $\mathrm{Ca}^{2+}$, com geometria "hemisférica ${ }^{(63)}$.

Os canais são um complexo de quatro subunidades: a formadora do poro aquoso $\alpha_{1}$ associada ao dímero $\alpha_{2} \delta$, e $\beta$, uma subunidade intracelular ${ }^{(64)}$. Foram clonadas e caracterizadas cinco classes da subunidade $\alpha_{1}$, denominadas A, B, C, D e E. As subunidades $\alpha_{1 \mathrm{~A}}$ e $\alpha_{1 \mathrm{~B}}$ constituem os canais de cálcio do tipo P/Q e N, respectivamente ${ }^{(65)}$. A subunidade $\alpha 1$ possui quatro DTMs (I-IV), a alça intracelular que conecta os DTMs II e III possui uma seqüência de aminoácidos (resíduos 718-963) denominada synprint (synaptic protein interaction, sítio de interação de proteínas sinápticas) que interage com as proteínas SNARE, sintaxina e SNAP-25(60).

Foi demonstrado que a sequiência synprint do canal de tipo P/Q interage com SNAP-25, causando uma inibição na dependência de voltagem do canal da ordem de $10 \mathrm{mV}^{(66)}$. Foi demonstrado, também, que o canal de tipo $\mathrm{N}$ interage com sintaxina ${ }^{(60)}$. A afinidade da interação do synprint com ambos os SNAREs (sintaxina e SNAP-25) é regulada pela concentração local de cálcio. Essa afinidade é mínima na concentração basal, é máxima no intervalo entre 10-30 $\mu \mathrm{M}$ (próxima do limiar para a liberação do NT) e é reduzida em concentrações $>100 \mu \mathrm{M}$ de cálcio. O canal de cálcio interage fracamente com os SNAREs na concentração basal de cálcio, interage fortemente no limiar e desacopla-se com o aumento da concentração de cálcio.

A inibição da atividade do canal de cálcio, pela ligação com SNAP-25 ou sintaxina, assegura que somente canais próximos às vesículas sinápticas, ancoradas pela formação de pré-complexos SNARE, estejam ativos ${ }^{(66)}$. A conexão entre a excitação (influxo de cálcio) e a exocitose do neurotransmissor é realizada pela proteína sinaptotagmina.

\subsubsection{Sinaptotagmina}

A família das sinaptotagminas é constituída por mais de uma dúzia de proteínas. As sinaptotagminas são proteínas integrais, de membrana com ampla distribuição em tecidos nervosos e não nervosos, em diferentes isoformas ${ }^{(67)}$. Essas proteínas caracterizam-se 
por possuirem um DTM embebido na MV e uma grande porção citoplasmática, contendo duas regiões homólogas ao domínio $\mathrm{C} 2$ da proteína kinase $\mathrm{C}$ $(\mathrm{PKC})^{(68)}$. Sabe-se que tal domínio, um motivo conservado de $\sim 130$ aa, regula a penetração dependente de cálcio da PKC em membranas e está presente em mais de sessenta proteínas com diferentes funções ${ }^{(69)}$. Nas sinaptotagminas, os dois domínios C2 desempenham funções diferentes.

$\mathrm{O}$ domínio $\mathrm{C} 2$ proximal em relação à $\mathrm{MV}$ da sinaptotagmina é denominado C2A. Sua estrutura foi definida recentemente ${ }^{(70)}$. Quando ligado a cálcio, esse domínio liga-se eletrostaticamente ${ }^{(71)}$ a fosfolipídios aniônicos (fosfatidilserina, em particular) em um complexo terciário ${ }^{(72)}$. Tal interação deve contribuir para a desestabilização das membranas, em analogia aos peptídeos de fusão virais, causando a fusão ${ }^{(73,74)}$. Simultaneamente à penetração na membrana, a sinaptotagmina interage com a base do complexo SNARE, próximo ao domínio transmembrana da sintaxina ${ }^{(75)}$. A cinética da resposta da sinaptotagmina ao aumento da concentração de cálcio coincide com a da exocito$\mathrm{se}^{(75)}$. Agindo como sensora de cálcio, peptídeo de fusão e reguladora da formação do complexo SNARE, a sinaptotagmina é a proteína chave para a liberação do NT.

O domínio $\mathrm{C} 2$ distal, denominado $\mathrm{C} 2 \mathrm{~B}$, medeia a heteroligomerização, dependente de cálcio, das sinaptotagminas I e II, presentes na mesma VSP(76). Essa oligomerização potencialmente organiza a maquinaria de fusão em um anel em torno do poro de fusão ${ }^{(77)}$. Tal domínio medeia também a associação independente de cálcio com o domínio synprint dos canais de cálcio, com a proteína adaptadora de clatrina $\mathrm{AP}^{(78)}$ e com $\beta$-SNAP ${ }^{(79)}$. Foi comprovado que a interação do domínio C2B com o domínio synprint dos canais de cálcio inibe a oligomerização da sinaptotagmina ${ }^{(78)}$. A interação seqüencial das proteínas com o domínio C2B seria um elo entre a exocitose e a endo$\operatorname{citose}^{(80)}$.

\section{Reciclagem vesicular}

Os processos de biogênese e transporte são lentos em comparação com a velocidade e a intensidade da fusão das vesículas, no terminal. Portanto, a maior parte das VSPs, presentes na zona ativa do terminal sináptico, provêm da reciclagem local das proteínas e membranas da $\mathrm{VS}^{(81)}$. A reciclagem ocorre por brotamento, após a segregação das proteínas sinápticas, a partir de projeções tubulares de endossomos primários ${ }^{(82)}$ ou de um novo compartimento celular chamado perissomo ${ }^{(83)}$ (contíguo à membrana plasmática, mas que não possui transferrina, um marcador para MP), sem a ocorrência de endossomos ${ }^{(84)}$. Outra possibilidade é que a reciclagem ocorra paralelamente, tanto diretamente da MP quanto de compartimentos intermediários, semelhantes a endossomos gerados pela invaginação e destacamento de grandes áreas da $\mathrm{MP}^{(85)}$. Além da topologia do compartimento de origem das vesículas, discute-se qual seria o principal meio molecular de reciclagem das vesículas.

\subsection{Endocitose}

No processo de endocitose consideraremos duas etapas: brotamento e fissão (Figura 5). Ainda não está estabelecido em qual domínio celular (MP, endossomo primário ou perissomo) se dá a endocitose das VS (ver Reciclagem vesicular), porém as proteínas envolvidas na endocitose, são razoavelmente conhecidas. A endocitose é realizada por uma superestrutura molecular, envolvendo vinte diferentes proteínas. As principais proteínas são a clatrina e a dinamina, que agem em duas fases distintas da endocitose: brotamento e fissão, respectivamente.

\subsubsection{Brotamento}

Na zona ativa do terminal pré-sináptico são visualizados "brotos" ou invaginações da membrana plasmática, recobertas por complexos moleculares, compostos por clatrina e adaptadores protéicos $(\mathrm{APs})^{(86)}$.

Os Adaptadores Protéicos (APs) são complexos protéicos, responsáveis pelo ancoramento da clatrina na membrana e pela interação com as proteínas de membrana que contêm sequiências peptídicas sinalizadoras, segregando-as nos brotos que, após a fissão da membrana de origem, formarão vesículas cobertas por clatrina (VCC) $)^{(87)}$.

Cada adaptador protéico (AP) é constituído por quatro subunidades denominadas adaptinas: duas cadeias grandes com $\sim 100 \mathrm{kDa}$ ( $\gamma$ e $\beta 1$ em AP1, $\alpha$ e $\beta 2$ em AP2, $\delta$ e $\beta 3$ em AP3 e $\varepsilon$ e $\beta 4$ em AP4), uma cadeia média com $\sim 50 \mathrm{kDa}(\mu$ 1-4 em AP1-4, respectivamente) e uma cadeia pequena com $\sim 20 \mathrm{kDa}(\sigma 1-$ 4 em AP1-4, respectivamente). As subunidades formam heterotetrâmeros que, visualizados através da técnica de sombreamento rotatório para microscopia eletrônica, apresentam-se como blocos com apêndices ou "cabeças com orelhas" ${ }^{(88)}$. As orelhas correspondem às extremidades $\mathrm{C}$-terminais das cadeias grandes e a cabeça contém os dois terços $\mathrm{N}$-terminais das cadeias grandes e as cadeias média e pequena. 

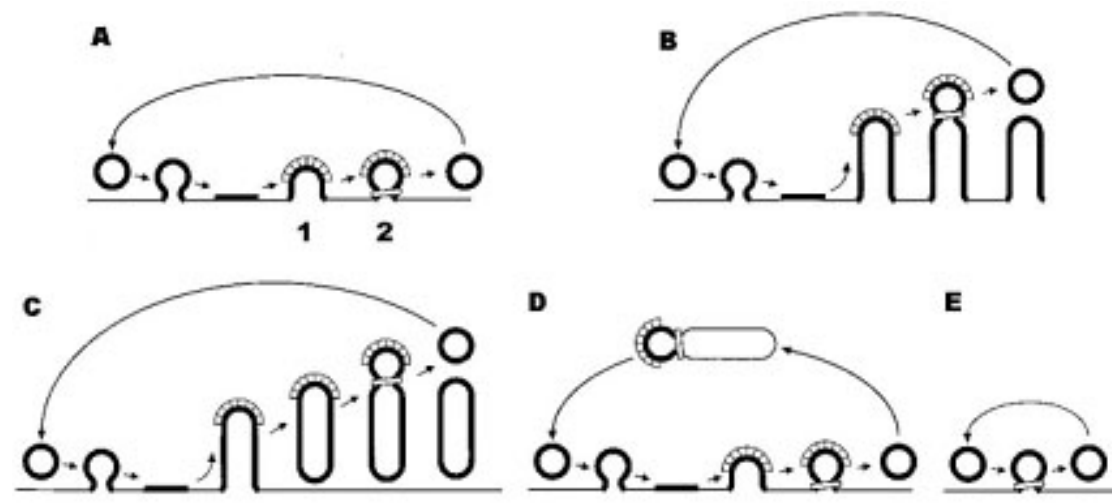

$\Leftrightarrow$ anel de dinarnina nominada LAP (Like AP180). Tal proteína apresenta a capacidade de se agregar à clatrina in vitro, sendo crucial na manutenção da uniformidade do tamanho das VSPs in vivo. Estudos experimentais com neurônios de D. melanogaster lap, mutantes para a LAP, demonstraram que a endocitose das VSP está severamente prejudicada nos mutantes, levando a depleção das VSPs nos terminais sinápticos, demonstrando, assim, a importância do mecanismo de endocitose mediado pela clatrina, na manutenção do pool de $\operatorname{VSP}^{(97)}$. Foi demonstrado que o AP180 é fosforilado e forma um complexo com AP2. O complexo AP180/AP2 possui maior afinidade por clatrina que os

As sequiências polipeptídicas, sinalizadoras, identificadas podem ser constituídas por: tirosina $(\mathrm{Y})^{(89)}$ ou uma dileucina $(\mathrm{LL})^{(90)}$. A tirosina é reconhecida somente em um motivo com a sequiência NPXY (sendo $\mathrm{N}$ asparagina, $\mathrm{P}$, prolina e $\mathrm{X}$ representa qualquer outro aa) ou Ypp $\phi$ (onde p representa um resíduo polar e $\phi$ um grande resíduo hidrofóbico). Os APs reconhecem sequiências sinalizadoras de tirosina e dileucina através de um sítio na cadeia $\mu$ e $\beta$, respectivamente ${ }^{(91,92)}$.

$\mathrm{Na}$ seqüência Ypp $\phi$, tal interação é mediada pela extremidade $\mathrm{N}$-terminal da cadeia $\mu 2$ da AP2, a qual apresenta uma $\beta$-estrutura, em que, dois bolsos interagem com a tirosina e o grande resíduo hidrofóbico de maneira semelhante ao reconhecimento de peptídeos contendo tirosina, realizado pelos domínios $\mathrm{SH} 2^{(93)}$. Sinaptotagmina e sinaptofisina possuem motivos contendo tirosina e interagem com AP2 ${ }^{(83)}$, enquanto sinaptobrevina-2 interage com $\mathrm{AP} 3$, provavelmente através de uma dileucina ${ }^{(94)}$.

Distintos APs estão associados com tipos específicos de vesículas cobertas por clatrina (VCC), conferindo diferentes propriedades a elas. Assim, complexos AP1 estão associados com a VCC derivada do complexo de Golgi, enquanto AP2 e AP3 estão associados à VCC relacionada a endossomos e $\mathrm{MP}^{(95)}$.

Outro adaptador protéico, encontrado em sinapses é o AP180, uma proteína monomérica com peso molecular de $\sim 94 \mathrm{kDa}$, específica do tecido nervoso ${ }^{(96)}$. Foram identificadas proteínas homólogas à AP180 em leveduras e em Drosophila melanogaster, esta de- adaptadores isolados, aumentando sua eficiência.

A clatrina é uma proteína trimérica com uma perna da clatrina é formada por um pequeno domínio de trimerização C-terminal, conectado a um domínio de $42 \alpha$-hélices em ziguezague com $~ 1600$ aa e um domínio globular de $\sim 330$ aa em sua extremidade $\mathrm{N}$ terminal. O domínio de $\alpha$-ziguezagues forma o longo filamento de $450 \AA$ da perna de clatrina e o domínio globular forma uma estrutura chamada $\beta$-propulsor ${ }^{(99)}$. O $\beta$-propulsor é constituído por sete "lâminas" de $\beta$ estruturas cada qual com quatro fitas dispostas em torno de um eixo de simetria. Entre as lâminas 1 e 2 existe uma cavidade que reconhece um motivo LLpL(-) [onde (-) representa um aa carregado negativamente, podendo ser um ácido aspártico ou um ácido glutâmico]. Tal motivo é denominado clathrin-box e está presente em todas as proteínas que interagem com clatrina, como os APs, as anfifisinas e a epsina ${ }^{(99,100)}$.

A associação dos trisceles de clatrina através de suas pernas em poliedros gera uma gaiola esférica que seria responsável pela deformação da membrana, formando um broto ${ }^{(101)}$.

As anfifisinas (isoformas 1 e 2) são proteínas que formam homo ou heterodímeros através de um domínio coiled-coil, altamente conservado, em sua extremidade $\mathrm{N}$-terminal. Também na região $\mathrm{N}$-terminal, está presente um sítio de ligação com lipídios, que é o responsável pela propriedade demonstrada pelas anfifisinas de se ligar à lipossomos e formar invaginaestrutura em forma de três pernas (triscele) ${ }^{(98)}$. Cada 
ções tubulares ${ }^{(102)}$. A região central do dímero de anfifisina possui domínios que interagem com clatrina e $\beta$-adaptina (AP2) $)^{(103)}$.

A região C-terminal das anfifisinas contém um domínio SH3 (homólogo à Src do tipo 3). Os domínios SH3 ligam-se a regiões ricas em prolina (PRD) de outras proteínas. Dinamina e sinaptojanina possuem PRDs e interagem com anfifisina ${ }^{(104,105)}$. A anfifisina agiria como uma ligação entre o brotamento e a fissão, através de sua interação com clatrina e o recrutamento da dinamina para os brotos recobertos por clatrina.

\subsubsection{Fissão}

A fissão do broto é realizada pela GTPase dinamina, que forma um colar espiralado em torno do poro. Dinamina é uma proteína homotetramérica com subunidades de $100 \mathrm{kDa}$. Ao contrário das Rabs, possui uma alta taxa de hidrólise de GTP e tal atividade pode ser regulada por diversas moléculas como microtúbulos, fosfolipídios ácidos, fosfatidil inositol 4,5 bisfosfato e domínios SH3 de outras proteínas que interagem com a região PRD ou o domínio PH (homólogo a plecstrina) da dinamina ${ }^{(106)}$. Essas moléculas estimulam a atividade de GTPase da dinamina através da estabilização dos agregados em forma de espiral em torno do poro MV-MP ${ }^{(107)}$. A hidrólise coordenada do GTP, nas diversas unidades de dinamina na espiral, induziria uma mudança conformacional que estrangularia o poro de liberação de NT, fechando-o ${ }^{(108)}$.

A dinamina age em conjunto com a endofilina1, que possui um domínio SH3 que interage com a região PRD da dinamina. A atividade da endofilina-1 é a de uma aciltransferase do ácido lisofosfatídico (LPAAT). A ação da endofilina-I influenciaria a curvatura da membrana fosfolipídica através da troca de fosfolipídios, em forma de cone invertido (lisofosfatídicos) por fosfolipídios em forma de cone (fosfatídi$\cos$ ), o que facilitaria o rompimento do poro e a liberação da vesícula ${ }^{(109)}$.

O recrutamento da dinamina para os poros das vesículas não recobertas por clatrina seria realizado pelos domínios $\mathrm{SH} 3$ da proteína intersectina que interage também com SNAP-25 através de seu domínio central altamente carregado ${ }^{(110)}$.

Sinaptofisina, uma proteína vesicular, liga se à dinamina em um modo dependente de $\mathrm{Ca}^{2}+$. O bloqueio dessa ligação produz inibição na reciclagem das vesículas sinápticas em uma alta freqüência de excitação, mas causa, também, um aumento no número de $\operatorname{VCC}^{(111)}$, o que demonstra a existência de uma via rápida de reciclagem vesicular, independente de clatrina. $\mathrm{O}$ aumento da concentração de cálcio mudaria o modo de reciclagem das VS para a reciclagem rápida, acoplando a atividade sináptica à reciclagem das vesículas, no terminal pré-sináptico ${ }^{(112)}$. A reciclagem controlada por sinaptofisina e dinamina, independente de clatrina, confirmaria o modelo kissand-run, proposto por Ceccarelli et al., em 1973(113), diferenciando a reciclagem das vesículas sinápticas de outros sistemas secretores cuja reciclagem depende unicamente da clatrina ${ }^{(111,112,113)}$. A endocitose mediada somente por dinamina ocorre com grande velocidade pois não há fusão completa da vesícula com a MP pré-sináptica.

Os resultados obtidos até agora indicam dois modos de reciclagem vesicular, ativos no terminal présináptico. Um modo universal, dependente de clatrina e outro específico, de células nervosas, apenas com a atuação da dinamina, seguindo o modelo kiss-andrun. Confirmando tais dados, experimentos em andamento na sinapse gigante da lula sugerem que a injeção do domínio SH3 da anfifisina, inibindo os sítios PRDs da dinamina, no terminal pré-sináptico, interrompeu a endocitose de vesículas cobertas por clatrina, como demonstrado por Shupliakov et al. ${ }^{(114)}$, mas a transmissão sináptica manteve-se estável ao longo do experimento (Llinás, Sugimori \& Moreira; em andamento).

Esperamos que a presente revisão seja útil como auxílio ao estudo da sinapse, despertando o interesse dos leitores para as pesquisas que aprofundarão nosso conhecimento acerca desse tópico, ao longo do século XXI. Como foi destacado, ao longo do texto, ainda existem muitos pontos obscuros a serem compreendidos. A compreensão do ciclo sináptico é a base da Neurociência e o caminho para o entendimento do funcionamento do sistema nervoso e do fenômeno consciente.

\section{AGRADECIMENTOS}

A Maria Dolores Ferreira, Maria Teresa P. Maglia e José Augusto Maulin pelo excelente auxílio técnico e a Rogério C. Ribeiro pela ilustração da figura 2, ao suporte técnico parcial da FAPESP, projetos 95/6206-0, 97/3026-6 e 99/ 3951-7, e a OEA, projeto AE/36-00 (JEM) e CAPES (GMA).

Para maior detalhamento de cada tópico, recomendamos a leitura das seguintes revisões $(8,10,15$, $22,34,38,59,69,87,97$ e 115). 
ARISI GM; NEDER L \& MOREIRA JE. The synaptic vesicle cycle: a molecular overview. Medicina, Ribeirão Preto, 34: 154-169, apr./june 2001.

ABSTRACT: The present review approaches a specific point in the synapse, probably the main one: the molecular interactions between the synaptic vesicle proteins and the presynaptic membrane proteins. A very precise language is talked between the vesicular and presynaptic membranes that allow the neurotransmitter release to the synaptic cleft. In recent years, the synaptic vesicle has been molecularly dissected, and it is probably the cell organelle with the most complete structural and kinetical description of its protein components. The discovery of families of homologue proteins in all eucariotic cells such as Rabs and SNAREs (SNAP receptors), demonstrated that the synaptic vesicle cycle depends on a refined interaction between a specific and universally distributed system of proteins that regulates the vesicle motion and fusion. The kinesin family is in charge of the mechanics for the anterograde transport of the raw material from the neuronal soma along microtubules in the axonal cytoskeleton. Sorting and flux control of the synaptic vesicle structural precursors is done by the Rab family of small GTPases. SNARE proteins make the fusion of the vesicles with the presynaptic terminal. Synaptotagmin regulates the formation of the SNARE complex in a calcium dependent mode. Although many of these proteins and their functions are well known, there is a large segment of knowledge on structure and interactions yet to be known.

UNITERMS: Synaptic Vesicle. Synaptic Proteins. Synapse. Neurotransmitters.

\section{REFERÊNCIAS BIBLIOGRÁFICAS}

1 - CROONE W. De ratione motus musculorum, 1664, tradução de Leonard G. Wilson; In: FULTON JF \& WILSON LG, eds., Selected readings in the history of physiology, $2^{\text {nd }} e d$., Charles C Thomas, Springfield, p.207-211, 1966.

2 - PURKINJE JE. Neueste untersuchungen aus der nerven- und hirn-anatomie. In: LLINÁS, R. The squid giant synapse: a model for chemical transmission. Oxford University Press, New York, p. 177-180, 1999.

3 - DEITERS O. Untersuchungen über Gehirn und Rückenmark. Braumschweig, Vieweg, 1865.

4 - RAMÓN y CAJAL S. Revista trimestral de histología normal y patológica, 1888; In: RAMÓN y CAJAL S. Histology of the nervous system, tradução de Swanson $N$ \& Swanson LW, Oxford University Press, New York, pp xxivxxv, 1995.

5 - BROCK LG, COOMBS JS \& ECCLES JC. The recording of potentials from motoneurones with an intracellular electrode. J Physiol 117: 431-460, 1952.

6 - AXELROD J. Nobel lectures, physiology or medicine 1963-1970. Elsevier Publishing, Amsterdam, 1971.

7 - POLLI LOPES AC; CASALETTI ROSA L; BELEBONI RO; PEREIRA RNR; VASC; NCELOS CAC \& MOREIRA JE. Aspectos moleculares da transmissão sináptica. Medicina, Ribeirão Preto 32: 167-188, 1999.

8 - CHAVRIER P \& GOUD B. The role of ARF and Rab GTPases in membrane transport. Curr Opin Cell Biol 11: 466-475, 1999.

9 - GONZALEZ Jr L \& SCHELLER RH. Regulation of membrane trafficking: structural insights from a Rab/effector complex. Cell 96: 755-758, 1999.
10 - NOVICK P \& ZERIAL M. The diversity of Rab proteins in vesicle transport. Curr Opin Cell Biol 9: 496-504, 1997.

11 - SUTTON RB; FASSHAUER D; JANH R \& BRÜNGER AT. Crystal structure of a SNARE complex involved in synaptic exocytosis at $2.4 \AA$ resolution. Nature 395: 347-353, 1998.

12 - UNGERMANN C; SATO K \& WICKNER W. Defining the functions of trans-SNARE pairs. Nature 396: 543-548, 1998.

13 - YANG B; GONZALEZ Jr L; PREKERIS R; STEEGMAIER M; ADVANI RJ \& SCHELLER RH. SNARE interactions are not selective. J Biol Chem 274:9 5649-5653, 1999.

14 - MAYER A. Intracellular membrane fusion: SNAREs only? Curr Opin Cell Biol 11: 447-452, 1999.

15 - BAJJALIEH SM. Synaptic vesicle docking and fusion. Curr Opin Neurobiol 9: 321-328, 1999.

16 - CALAKOS N \& SCHELLER RH. Synaptic vesicle biogenesis, docking and fusion: a molecular description. Physiol Rev 76: 1-29, 1996.

17 - MAINS RE \& EIPPER BA. Peptides. In: SIEGEL GJ; AGRANOFF BW; ALBERS RW; FISHER SK \& UHLER MD, eds., Basic Neurochemistry: molecular, cellular and medical aspects, $6^{\text {th }}$ ed., Lippincott-Raven, Philadelphia, pp. 363-382, 1999.

18 - KUHAR MJ; COUCEYRO PR \& LAMBERT PD. Cathecolamines. In: SIEGEL GJ; AGRANOFF BW; ALBERS RW; FISHER SK \& UHLER MD, eds., Basic Neurochemistry: molecular, cellular and medical aspects, $6^{\text {th }}$ ed., Lippincott-Raven, Philadelphia, pp. 243-262, 1999.

19 - TSUKITAS \& ISHIKAWA H. The movement of membraneous organelles in axons. Electron microscopic identification of anterogradely and retrogradely transported organelles. $\mathbf{J}$ Cell Biol 84: 513-530, 1980 
20 - RÉGNIER-VIGOUROUX A \& HUTTNER WB. Biogenesis of small synaptic vesicles and synaptic-like microvesicles. Neurochem Res 18: 59-64, 1993.

21 - ANANT JS; DESNOYERS L; MACHIUS M; DEMELER B, HANSEN JC; WESTOVER KD; DEISENHOFE J \& SEABRA MC. Mechanisms of Rab geranylgeranylation: formation of the catalityc ternary complex. Biochemistry 37: 1255912568, 1998.

22 - ZHANG H; SEABRA MC \& DEISENHOFER J. Crystal structure of Rab geranylgeranyltransferase at $2.0 \AA$ resolution. Structure 8: 241-251, 2000.

23 - ALLAN BB; MOYER BD \& BALCH WE. Rab1 recruitment of p115 into a cis-SNARE complex: programming budding COPII vesicles for fusion. Science 289: 444-448, 2000.

24 - OSTERMEIER C \& BRÜNGER AT. Structure basis of Rab effector specificity: crystal structure of the small $G$ protein Rab3A complexed with the effector domain of Rabphilin3A. Cell 96: 363-374, 1999.

25 - KATO M; SASAKI T; OHYA T; NAKANISHI H; NISHIOKA H; IMAMURA M \& TAKAI Y. Physical and functional interaction of Rabphilin-3A with $\alpha$-actinin. J Biol Chem 271: 3177531778, 1996.

26 - WATERS MG \& PFEFFER SR. Membrane tethering in intracelular transport. Curr Op Cell Biol 11: 453-459, 1999.

27 - GUO W; ROTH D, WALCH-SOLINEMA C \& NOVICK P. The exocyst is an effector for Sec4p, targeting secretory vesicles to sites of exocytosis. EMBO J 18: 1071-1080, 1999.

28 - CAO X; BALLEW N \& BARLOWE C. Initial docking of ERderived vesicles requires Uso1p and Ypt1 but is independent of SNARE proteins. EMBO J 17: 2494-2503, 1998.

29 - HIROKAWA N; NODA Y \& OKADA Y. Kinesin and dynein superfamily proteins in organelle transport and cell division. Curr Opin Cell Biol 10: 60-75, 1998

30 - OKADA Y; YAMAZAKI H; SEKINE-AIZAWA Y \& HIROKAWA $\mathrm{N}$. The neuron-specific kinesin superfamily KIF1A is a unique monomeric motor for anterograde axonal transport of synaptic vesicle percursors. Cell 81: 769-780, 1995.

31 - YAMAZAKI H; NAKATA T; OKADA Y \& HIROKAWA N. Cloning and characterization of KAP3: a novel kinesin superfamily-associated protein of KIF3A/3B. Proc Natl Acad Sci USA 93: 8443-8448, 1996.

32 - ECHARD A; JOLLIVET F; MARTINEZ O; LACAPÈRE JJ; ROUSSELET A; JANOUIEX-LEROSEY I \& GOUD B. Interaction of a Golgi-associated kinesin-like protein with Rab6. Science 279: 580-585, 1998.

33 - LIU Y \& EDWARDS RH. The role of vesicular transport proteins in synaptic transmission and neural degeneration. Annu Rev Neurosci 20: 125-156, 1997.

34 - MCINTIRE SL; REIMER RJ; SCHUSKE K; EDWARDS RH \& JORGENSEN EM. Identification and characterization of the vesicular GABA transporter. Nature 389: 870-876, 1997.

35 - FEANY MB; LEE S; EDWARDS RH \& BUCKLEY KM. The synaptic vesicle protein SV2 is a novel type of transmembrane transporter. Cell 70: 861-867, 1992.

36 - SCHIVELLAE; BATCHELOR RH \& BAJJALIEH SM. Isoformspecific, calcium-regulated interaction of the synaptic vesicle proteins SV2 and synaptotagmin. J Biol Chem 271: 2777027775, 1996.
37 - JANZ R; HOFMANN K \& SÜDHOF TC. SVOP, an evolutionarily conserved synaptic vesicle protein, suggests novel transport functions of synaptic vesicles. J Neurosci 18: 9269-9281, 1998.

38 - REIMER RJ; FON EA \& EDWARDS RH. Vesicular neurotransmitter transport and the presynaptic regulation of quantal size. Curr Opin Neurobiol 8: 405-412, 1998.

39 - PALADE GE. Intracellular aspects of the process of protein synthesis. Science 189: 347-358, 1975.

40 - SÖLLNER TH; WHITEHEART SW; BRUNNER M;ERDJUMENTBROMAGE H; GEROMANOS S; TEMPST P \& ROTHMAN JE. SNAP receptors implicated in vesicle targeting and fusion. Nature 362: 318-324, 1993.

41 - BENNET MK \& SCHELLER RH. The Molecular Machinery for Secretion is Conserved from Yeast to Neurons. Proc Natl Acad Sci USA 90: 2559-2563, 1993.

42 - BLATT MR; LEYMAN B \& GEELEN D. Tansley Review No. 108 - Molecular events of vesicle trafficking and control by SNARE proteins in plants. New Phytol 144: 389-418, 1999.

43 - BAUMERT M; MAYCOXPR,;NAVONE F; DE CAMILLIP \& JAHN R. Synaptobrevin: an integral membrane protein of 18000 daltons present in smal synaptic vesicles of rat brain. EMBO J 8: 379-384, 1989.

44 - BENNET MK, CALAKOS N \& SCHELLER RH. Syntaxin: a synaptic protein implicated in docking of synaptic vesicles at presynaptic active zones. Science 257: 255-259, 1992.

45 - OYLER GA; HIGGINS GA; HART RA; BATTENBERG E, BILLINGSLEY M, BLOOM FE \& WILSON MC. The identification of a novel synaptossomal-associated protein, SNAP. 25 , differentially expressed by neuronal subpopulations. J Cell Biol 109: 3039-3052, 1989.

46 - WEIMBS T; LOW SH; CHAPINSJ; MOSTOV KE; BUCHER P \& HOFMANN K. A conserved domain is present in different families of vesicular fusion proteins: a new superfamily. Proc Natl Acad Sci USA 94: 3046-3051, 1997.

47 - KATZL; HANSONPI; HEUSER JE \& BRENNWALD P. Genetic and morphological analyses reveal a critical interaction between the C-termini of two SNARE proteins and a parallel four helical arrangement for the exocytic SNARE complex. EMBO J 17: 6200-6209, 1998.

48 - FASSHAUER D, SUTTON RB, BRÜNGER AT \& JAHN R. Conserved structural features of the synaptic fusion complex: SNARE proteins reclassified as Q- and R-SNAREs. Proc Natl Acad Sci USA 95: 15781-15786, 1998.

49 - SÖLLNER TH; BENNETT MK; WHITEHEART SW; SCHELLER $\mathrm{RH} \&$ ROTHMAN JE. A protein assembly-disassembly pathway in vitro that may correspond to sequential steps of synaptic vesicle docking, activation and fusion. Cell 75: 409-418, 1993.

50 - HESS DT; SLATER TM; WILSON MC \& SKENE JHP. The 25 $\mathrm{kDa}$ synaptosomal-associated protein SNAP-25 is the major methionine-rich polypeptide in rapid axonal-transport and a major substrate for palmitoylation in adult CNS. J Neurosci 12: 4634-4641, 1992.

51 - BENTZ J. Membrane fusion mediated by coiled coils: a hypotesis. Biophys J 78: 886-900, 2000.

52 - DURREL SR; MARTIN I; RUYSSCHAERT JM; SHAI Y \& BLUMENTHAL R. What studies of fusion peptides tell us 
about viral envelope glycoprotein-mediated membrane fusion. Mol Membr Biol 14: 97-112, 1997.

53 - RAZINKOV VI; MELIKYAN GB; EPAND RM; EPAND RF \& COHEN FS. Effects of spontaneous bilayer curvature on influenza virus-mediated fusion pores. J Gen Physiol 112: 409-422, 1998.

54 - JAHN R \& SÜDHOF TC. Membrane fusion and exocytosis. Annu Rev Biochem 68: 863-911, 1999.

55 - PATEL $S$ \& LATTERICH M. The AAA team: related ATPases with diverse functions. Trends Cell Biol 8: 65-71, 1998.

56 - NAGIEC EE, BERNSTEIN A \& WHITEHEART SW. Each domain of the $\mathrm{N}$-ethylmaleimide-sensitive fusion protein contributes to its transport activity. J Biol Chem 270: 2918229188, 1995.

57 - TOLAR LA \& PALLANK L. NSF function in neurotransmitter release involves rearrangement of the SNARE complex downstream of synaptic vesicle docking. J Neurosci 18: 10250-10256, 1998.

58 - SMITH SJ \& AUGUSTINE GJ. Calcium ions, active zones and synaptic transmitter release. Trends Neurosci 11: 458464, 1988.

59 - PUMPLIN DW; REESE TS \& LLINÁS R. Are the presynaptic membrane particles the calcium channels? Proc Natl Acad Sci USA 78: 7210-7214, 1981.

60 - CATERRAL WA. Interactions of presynaptic $\mathrm{Ca}^{2+}$ channels and SNARE proteins in neurotransmitter release. Ann NY Acad Sci 868: 144-159, 1999.

61 - LLINÁS R; SUGIMORI M \& SILVER RB. Microdomains of high calcium concentration in a presynaptic terminal. Science 256: 677-679, 1992.

62 - HEIDELBERGER R, HEINEMANN C, NEHER E \& MATHEWS G. Calcium dependence of the rate of exocytosis in a synaptic terminal. Nature 371: 513-515, 1994.

63 - LLINÁS R. The squid giant synapse: a model for chemical transmission. Oxford University Press, New York, 1999.

64 - CATERRAL WA. Structure and function of voltage-gated ion channels. Ann Rev Biochem 65: 493-531, 1995.

65 - ZHANG J-F, RANDALLAD, ELLINOR PT, HORNE WA, DATHER WA, TANABE T, SCHWARZ TL \& TSIEN RW. Distinctive pharmacology and kinetics of cloned neuronal $\mathrm{Ca}^{2+}$ channels and their possible counterparts in the mammalian CNS neurons. Neuropharmacology 32: 1075-1088, 1993.

66 - ZHONG H, YOKOYAMA T, SCHEUER T \& CATERRAL WA. Reciprocal regulation of $\mathrm{P} / \mathrm{Q}$-type $\mathrm{Ca}^{2+}$ channels by SNAP25, synatxin and synaptotagmin. Nat Neurosci 2: 939-941, 1999.

67 - SÜDHOF TC \& RIZO J. Synaptotagmins: C-2-domain proteins that regulate membrane traffic. Neuron 17: 379388, 1996.

68 - PONTING CP \& PARKER PJ. Extending the C2 domain family: C2s in PKCs delta, epsilon, eta, theta, phospholipases, GAPs, and perforin. Protein Sci 5: 162-166, 1996.

69 -SCHIAVO G, OSBORNE SL \& SGOUROS JG. Synaptotagmins: More isoforms than functions? Biochem Biophys Res Commun 248: 1-8, 1998.
70 - SUTTON RB; DAVLETOV BA; BERGHUIS AM; SUDHOF TC; SPRANG SR Structure of the first C-2 domain of synaptotagmin 1 . A novel $\mathrm{Ca}^{2+} /$ phospholipid-binding fold. Cell 80: 929-938, 1995.

71 - DAVLETOV B, PERISIC O \& WILLIAMS RL. Calciumdependent membrane penetration is a hallmark of the $\mathrm{C} 2$ domain of cytosolic phospholipase A2 whereas the C2A domain of synaptotagmin binds membranes electrostatically. J Biol Chem 273: 19093-19096, 1998.

72 - CHAPMAN ER \& DAVIS AF. Direct interaction of a $\mathrm{Ca}^{2+}$. binding loop of synaptotagmin with lipid bilayers. J Biol Chem 273: 13995-14001, 1998.

73 - BROSE N; PETRENKO AG; SÜDHOF TC \& JAHN R. Synaptotagmin - a calcium sensor on the synaptic vesicle surface. Science 256: 1021-1025, 1992.

74 - MIKOSHIBA K; FUKUDA M; MOREIRA JE; LEWIS FMT, SUGIMORI M; NIINOBE M \& LLINÁS R. Role of the C2A domain of synaptotagmin in transmitter release as determined by specific antibody injection into the squid giant synapse preterminal. Proc Natl Acad Sci USA 92: 1070310707, 1995.

75 - DAVIS AF; BAI J; FASSHAUER D; WOLOWICK MJ; LEWIS JL \& CHAPMAN ER. Kinetics of synaptotagmin responses to $\mathrm{Ca}^{2+}$ and assembly with the core SNARE complex onto membranes. Neuron 24: 363-376, 1999.

76 - OSBORNE SL; HERREROS J; BASTIAENS PIH \& SCHIAVO G. Calcium-dependent oligomerization of synaptotagmins I and II. J Biol Chem 274: 59-66, 1999.

77 - FERNANDEZ-CHACON R \& ALVAREZ DE TOLEDO G. Cytosolic calcium facilitates release of secretory products after exocytotic vesicle fusion. FEBS Lett 363: 221-225, 1995.

78 - CHAPMAN ER; DESAI RC; DAVIS AF \& TORNEHL CK. Delineation of the oligomeriztion, AP-2 binding and synprint binding region of the $\mathrm{C} 2 \mathrm{~B}$ domain of synaptotagmin. $\mathbf{J}$ Biol Chem 273: 32966-32972, 1998.

79 - SCHIAVO G; GMACHL MJS; STENBECK G; SÖLLNER TH; ROTHMAN JE. A possible docking and fusion particle for synaptic transmission. Nature 378: 733-736, 1995.

80 - FUKUDAM; MOREIRAJE; LEWIS FMT; SUGIMORI M; NIINOBE M; MIKOSHIBA K \& LLINÁS R. Role of the C2B domain of synaptotagmin in vesicular release and recycling as determined by specific antibody injection into the squid giant synapse preterminal. Proc Natl Acad Sci USA 92: 1070810712, 1995.

81 - DE WIT H; LICHTENSTEIN Y;GEUZE HJ; KELLY RB; VAN DER SLUISS P \& KLUMPERMAN J. Synaptic vesicles form by budding from tubular extensions of sorting endosomes in PC12 cells. Mol Biol Cell 10: 4163-4176, 1999.

82 - HANNAH MJ; SCHMIDT A \& HUTTNER WB. Synaptic vesicle biogenesis. Annu Rev Cell Dev Biol 15: 733-798, 1999.

83 - SCHMIDT A; HANNAH MJ \& HUTTNER WB. Synaptic-like microvesicles of neuroendocrine cells originate from a novel compartment that is continuous with the plasma membrane and devoid of transferrin receptor. J Cell Biol 137:2 445458, 1997.

84 - DESNOS C; CLIFT-O'GRADY L \& KELLY RB. Biogenesis of synaptic vesicles in vitro. J Cell Biol 130: 1041-1049, 1995. 
85 - TAKEI K; MUNDIGL O; DANIELL L \& DE CAMILLI P. The synaptic vesicle cycle: a single vesicle budding step involving clathrin and dynamin. J Cell Biol 133: 11237-1250, 1996.

86 - HEUSER JE \& REESE TS. Evidence for recycling of synaptic vesicles membrane during transmitter release at the frog neuromuscular junction. J Cell Biol 57: 315-344, 1973.

87 - KIRCHHAUSEN T. Adaptors for clathrin-mediated traffic. Annu Rev Cell Dev Biol 15: 705-732, 1999.

88 - HEUSER JE \& KEEN J. Deep-etch visualization of proteins involved in clathrin assembly. J Cell Biol 107: 877-886, 1988.

89 - BONIFACINO JS \& DELL'ANGELICA EC. Molecular bases for the recognition of tyrosine-based sorting signals. J Cell Biol 145: 923-926, 1999.

90 - GEISLER C; DIETRICH J; NIELSEN BL; KASTRUP J; LAURITSEN JPH; ØDUM N \& CHRISTENSEN MD. Leucinebased Receptor Sorting Motifs Are Dependent on the Spacing Relative to the Plasma Membrane. J Biol Chem 273: 21316 21323,1998.

91 - OHNO H; STEWART J; FOURNIER MC;BOSSHART H; RHEE I, MIYATAKE S; SAITO T; GALLUSSER A; KIRCHHAUSEN T \& BONIFACINO JS. Interaction of tyrosine-based sorting signals with the medium chains of clathrin-associated protein. Mol Biol Cell 6: 398-398, Suppl. S, 1995.

92 - RAPOPORT I; CHEN YC; CUPERS P; SHOELSON SE \& KIRCHHAUSEN T. Dileucine-based sorting signals bind to the beta chain of AP-1 at a site distinct and regulated differently from the tyrosine-based motif-binding site. EMBO J 17: 2148-2155, 1998

93 - OWEN DJ \& EVANS PR. A structural explanation for the recognition of tyrosine-based endocytotic signals. Science 282: $1327-1332,1998$

94 - SALEM N, FAÚNDEZ V, HORNG J-T \& KELLY RB. A v-SNARE participates in synaptic vesicle formation mediated by the AP3 adaptor complex. Nat Neurosci 1: 551-556, 1998

95 - MCMAHON HT. Endocytosis: an assembly protein for clathrin cages. Curr Biol 9: R332-R335, 1999.

96 - MURPHY JE; PLEASURE IT; PUSZKIN S; PRASAD K \& KEEN $\mathrm{JH}$. Clathrin assembly protein AP-3. The identity of the $155 \mathrm{~K}$ protein, AP 180, and NP185 and demonstration of a clathrin binding domain. J Biol Chem 266: 4401-4408, 1991.

97 - MARSH M \& MCMAHON HT. The structural era of endocytosis. Science 285: 215-219, 1999.

98 - JIN AJ \& NOSSAL R. Rigidity of triskelion arms and clathrin nets. Biophys J 78: 1183-1194, 2000.

99 - TER HAAR E, HARRISON SC \& KIRCHHAUSEN T. Peptidein-groove interactions link target proteins with the $\beta$-propeller of clathrin. Proc Natl Acad Sci USA 97: 1096-1100, 2000

100 - DELL'ANGELICA EC, KLUMPERMAN J, STOORVOGEL W \& BONIFACINO JS. Association of the AP-3 adaptor complex with clathrin. Science 280: 431-434, 1998

101 - CROWTHER RA \& PEARSE BMF. Assembly and packing of clathrin into coats. J Cell Biol 91: 790-797, 1981.
102 - TAKEI K; SLEPNEV VI; HAUCKE V \& DE CAMILLI P. Functional partership between amphiphysin and dynamin in clathrin-mediated endocytosis. Nature Cell Biol 1: 3339, 1999.

103 - SLEPNEV VI; OCHOA GC; BUTLER MH \& DE CAMILLI P. Tandem arrangement of the clathrin and AP-2 binding domain in amphiphysin 1 and disruption of clathrin coat function by amphiphysin fragments comprising these sites. J Biol Chem 275: 17583-17589, 2000.

104 - GRABS D, SLEPNEV VI, SONGYANG Z, DAVID C, LYNCH $M$, CANTLEY LC \& DE CAMILLI P. The SH3 domain of amphiphysin binds the proline-rich domain of dynamin at a single site that defines a new $\mathrm{SH} 3$ binding consensus sequence. J Biol Chem 272: 13419-13425, 1997.

105 - DE HEUVEL E;BELL AW; RAMJAUN AR WONG K; SOSSIN WS \& MCPHERSON PS. Identification of the major synaptojanin-binding proteins in brain. J Biol Chem 272: 8710-8716, 1997.

106 - WARNOCK DE, HINSHAW JE \& SCHMID SL. Dynamin self assembly stimulates its GTPase activity. J Biol Chem 271: 22310-22314, 1996.

107 - WARNOCK DE \& SCHMID SL. Dynamin GTPase: a force generating molecular switch. Bioessays 18: 885-893, 1996.

108 - SWITZER SM \& HINSHAW JE. Dynamin undergoes a GTPdependent conformational change causing vesiculation. Cell 93: 1021-1029, 1998

109 - SCHMIDT A; WOLDE M; THIELE C; FEST W; KRATZIN H PODTELEJNIKOV AV, WITKE W, HUTTNER WB \& SÖLING $\mathrm{H}$-D. Endophilin I mediates synaptic vesicle formation by transfer of arachidonate to lysophosphatidic acid. Nature 401: 133-141, 1999.

110 - OKAMOTO M; SCHOCH S \& SÜDHOF TC. EHSH1/ Intersectin, a protein that contains $\mathrm{EH}$ and $\mathrm{SH} 3$ domains and binds to dynamin and SNAP-25. J Biol Chem 274: 18446-18454, 1999.

111 - DALY C; SUGIMORI M; MOREIRA JE; ZIFF EB \& LLINÁS R. Synaptophysin regulates clathrin-independent (kiss-andrun) synaptic vesicle endocytosis. Proc Natl Acad Sci USA 97: 6120-6125, 2000

112 - ALES E; TABARES L, POYATO JM; VALERO V; LINDAU M \& DE TOLEDO GA. High calcium concentrations shift the mode of exocytosis to the kiss-and-run mechanism. Nature Cell Biol 1: 40-44, 1999.

113 - CECCARELLI B; HURLBUT WP \& MAURO A. Turnover of transmitter and synaptic vesicles and the frog neuromuscular junction. J Cell Biol 57: 499-524, 1973.

114 - SHUPLIAKOV O; LÖW P, GRABS D, GAD H, CHEN H, DAVID C, TAKEI K, DE CAMILLI P \& BRODIN L. Synaptic vesicle endocytosis impaired by disruption of dynamin-SH3 domain interactions. Science 276: 259-263, 1997.

115 - SÜDHOF TC. The synaptic vesicle cycle: a cascade of protein-protein interactions. Nature 375: 645-653, 1995.

Recebido para publicação em 20/10/2000

Aprovado para publicação em 26/06/2001 